\title{
THE TREATMENT OF AMOEBIC DYSENTERY
}

\author{
S. Bell, M.D., M.R.C.P.(EdIN.), D.T.M. \& H. \\ Department of Clinical Tropical Medicine, Hospital for Tropical Diseases, London, N.W.I
}

Diagnosis of infection with Entamoeba histolytica remains the most important practical problem, and is the essential pre-requisite for effective treatment. Without reliable parasitological diagnosis follow-up examinations are virtually useless, and attempts to assess the curative value of courses of treatment are worthless. In many tropical and sub-tropical areas carriers of the cystic form of the parasite are so numerous that, until very recently, radical treatment of them was outside the bounds of possibility. Thus the main effort there has been directed to treatment of the patient suffering from amoebic dysentery or one of its complications.

\section{Status of the Parasite}

Fundamental research both on the amoebic parasite and on the host parasite relation is of great importance, for knowledge is incomplete about the pathogenicity of various strains of the organism, and about the factors which may precipitate acute amoebic dysentery and hepatic abscess or which cause the parasite to remain in the cystic stage as a latent infection.

Hoare $^{2}$ has attempted to clarify the nomenclature of the large and small race parasites. The small race, formerly named Entamoeba histolytica minuta, is now named Entamoeba hartmanni. It produces cysts of mean diameter Io $\mu$ or less. This parasite is not believed to be pathogenic. Ridley and Schofield 5 reported a study of the symptoms related to infection with it and showed no correlation with symptoms of dysentery. The large race parasite Entamoeba histolytica produces cysts of mean diameter about $20 \mu$. It may be a nonpathogenic commensal, as is probably the case with those harbouring it in non-tropical environments. On the other hand some strains are virulent pathogens, ingesting red cells, invading the tissues, and causing amoebic dysentery and its complications. As yet, only detailed investigation by an experienced worker, using three-week-old weanling rats as experimental animals, will reveal differences in pathogenicity of various strains of the large race parasites. ${ }^{4}$

\section{Recent Advances in Drug Therapy}

The groups of drugs available for the treatmene of intestinal amoebiasis are:

(I) Emetine and its compounds especially emetine bismuth iodide.

(2) Iodoquinoline compounds such as dihydroxy-iodoquinoline (Yatren, Chiniofon, Enterovioform, etc.).

(3) Organic arsenicals such as Carbasone.

(4) Antibiotics.

(5) Synthetic compounds and others, e.g.? Camoform, Glaucarubin, compounds of dichloroacet - 4 - hydroxy - n - methylanilide (Entamide).

\section{Acute Amoebic Dysentery}

The drug of choice to relieve acute symptoms emetine hydrochloride I gr. daily (6o mg.) by subcutaneous injection for four to seven days This drug alone, however, even in a longer course, does not result in a high radical cure rate. $B y=$ using it to control the acute symptoms and theno changing to oral administration of emetine bismuth iodide (EBI) a much better cure rate can be achieved. EBI should be dispensed in fresh gelatin capsules and the adult patient is given 2 course of $3 \mathrm{gr}$. (180 mg.) each night for ten nights. The drug causes gastric irritation with nausea and 3 vomiting, and colonic irritation with diarrhoea. To diminish the former the patient is given a meal? at 6 p.m. and then no more food or drink untilo next morning. At 9 p.m. he is given a rapidlyacting sedative of which soluble phenobarbitoneo gr. I (6o mg.) by subcutaneous injection is suitable; and at ro p.m. he is given the capsules containing EBI. It is common for the patient ton awaken at about 2 a.m. feeling nauseated and hen may retch or vomit a little gastric juice containing $\omega_{\sigma}$ a few granules of the drug. If much of the dose is returned an additional dose is given at the end of the normal course. This gastric irritation oftenos diminishes after the first few nights. It is probable that confining the patient to bed witho only the use of the bathroom and toilet helps to. 
lessen the trouble. The diarrhoea due to EBI commonly begins after about five or six days on treatment. It is most important to recognize that this is a side-effect of the drug, and not to regard it as an indication for prolonged treatment. Some alleviation can be obtained by the use of a simple kaolin mixture and the patient should be assured that the diarrhoea will abate when the drug is stopped.

In the course of trials of many new drugs none has been found as yet which results in a higher cure rate than EBI when properly administered. ${ }^{6}$

\section{Carriers of Amoebic Infection}

Whether or not to treat those excreting cysts who have no dysenteric symptoms depends on the history of the patient's condition. If he has suffered from bowel trouble and particularly if he has come from a tropical or subtropical area, and if the mean diameter of the cysts is greater than $10 \mu$, it is wise to give treatment. EBI without preliminary emetine injections is most likely to cure the patient.

Trials with many other drugs have been made in the hope of finding one as effective but without the side-effects of EBI.

Among the antibiotics tried are fumagillin and paromycin (Humatin, Parke Davis \& Co.). The record of a trial of fumagillin was included in the report by Woodruff et al. ${ }^{6}$ Of 31 patients excreting cysts 27 had follow-up examinations after treatment and one relapsed. Of three who had trophozoites in their bowel contents, two did not respond to the drug. Indigestion and desquamation of skin especially on the hands were toxic effects. A trial with Humatin was reported by Bell and Woodruff. 1 Twenty patients who were excreting cysts were treated and 19 were followed-up for periods ranging from one month to over one year with one relapse. Diarrhoea was a side-effect of this drug.

The most promising of the newer synthetic compounds has been Entamide furoate (now being sold under the name Furamide, Boots Pure Drug Co. Ltd.). Details are reported by Woodruff and Bell ${ }^{7}$ and a field trial in a tropical area is reported by Marsden. ${ }^{3}$ This drug has given very good results in the radical cure of cyst passers and apart from some flatulence there have been no sideeffects. It is possible that this drug may prove suitable as a replacement for EBI for use in acute dysentery after symptoms have been controlled by the use of emetine hydrochloride, for use in treating cyst passers as out-patients, and for use in repeated courses for food-handlers in catering establishments in tropical and sub-tropical areas. The drug is supplied in tablets each of $0.5 \mathrm{~g}$. and the dose has been calculated on the basis of $20 \mathrm{mg}$. per kg. body weight per day for ten days.

\section{Treatment of Hepatic Complications of Amoebic Infection}

Apart from aspiration of an abscess in the liver, which is more successful and safer than open operation and drainage (except in the uncommon case of an abscess in the left lobe), the treatment of hepatic amoebiasis is with emetine hydrochloride by subcutaneous injection in a dose of I gr. (60 mg.) daily for ten days; or with chloroquine diphosphate or sulphate by mouth in a dose of $300 \mathrm{mg}$. of base thrice daily for two days and then $150 \mathrm{mg}$. of base thrice daily for at least 12 days. Where the parasites are present in the bowel contents treatment with one of the drugs already mentioned is also required. Chloroquine has no appreciable effect on these.

\section{REFERENCES}

I. BELL, S., and WOODRUFF, A. W. (1960), Amer. F. trop. Med. 9, 155 .

2. HOARE, C. A. (1958), Rice Institute Pamphlet, 45, 27.

3. MARSDEN, P. D. (1960), Trans. roy. Soc. trop. Med. Hyg. 54, 396.

4. NEAL, R. A. (1951), Ibid,. 44, 439.

5. RIDLEY, D. S., and SCHOFIELD, F. D. (1957), Ibid., $51,518$.

6. WOODRUFF, A. W., BELL, S., and SCHOFIELD, F. D. (1956), Ibid., 50, 114

7. WOODRUFF, A. W., and BELL, S. (1960), Ibid., 54, 389. 